\title{
Chronic disease and chronic disease risk factors among First Nations, Inuit and Métis populations of northern Canada
}

\author{
S. G. Bruce, PhD; N. D. Riediger, MSc; L. M. Lix, PhD
}

This article has been peer reviewed.

Tweet this article

\begin{abstract}
Introduction: Aboriginal populations in northern Canada are experiencing rapid changes in their environments, which may negatively impact on health status. The purpose of our study was to compare chronic conditions and risk factors in northern Aboriginal populations, including First Nations (FN), Inuit and Métis populations, and northern non-Aboriginal populations.
\end{abstract}

Methods: Data were from the Canadian Community Health Survey for the period from 2005 to 2008. Weighted multiple logistic regression models tested the association between ethnic groups and health outcomes. Model covariates were age, sex, territory of residence, education and income. Odds ratios (ORs) are reported and a bootstrap method calculated $95 \%$ confidence intervals (CIs) and $p$ values.

Results: Odds of having at least one chronic condition was significantly lower for the Inuit (OR $=0.59 ; 95 \% \mathrm{CI}: 0.43-0.81$ ) than for non-Aboriginal population, but similar among FN, Métis and non-Aboriginal populations. Prevalence of many risk factors was significantly different for Inuit, FN and Métis populations.

Conclusion: Aboriginal populations in Canada's north have heterogeneous health status. Continued chronic disease and risk factor surveillance will be important to monitor changes over time and to evaluate the impact of public health interventions.

Keywords: Aboriginal, First Nations, Inuit, Métis, chronic disease, northern Canada

\section{Introduction}

Aboriginal populations in Canada's north comprise three distinct groups, First Nations (FN), Inuit and Métis, each with their own histories, lifeways and relationships with the Government of Canada. Canada's northern territories, the Yukon, Northwest Territories (NWT) and Nunavut, have the largest proportion of Aboriginal people of any region in Canada. Overall, $40 \%$ of northern Canadians living in the territories are Aboriginal, compared to only $4 \%$ of the total Canadian population. ${ }^{1}$ In Nunavut, $85 \%$ of the population is Aboriginal, over $90 \%$ of whom are Inuit.
In the NWT, $50 \%$ of the population is Aboriginal (FN, 61\%; Inuit, 20\%; Métis, $17 \%)$ and in the Yukon, $25 \%$ of the population is Aboriginal (FN, $83 \%$; Métis, $11 \%$; Inuit, $4 \%){ }^{*}$

In the past half century, the Aboriginal populations of northern Canada have undergone a significant health transition characterized by a decline in infectious diseases and an increase in chronic conditions such as diabetes, obesity, heart disease and respiratory illnesses. This is paralleled by an increase in social problems such as violence, accidents and substance abuse. ${ }^{2}$ These phenomena are strongly interrelated through the effects of colonization and the subsequent changes in both physical and social environments. ${ }^{3}$

The epidemiological transition is proceeding at a different pace for Aboriginal peoples in southern and northern Canada. As Lix et al. ${ }^{4}$ described, the burden of chronic diseases and risk factors for chronic diseases is high in the south and emerging in the north. Chronic disease and risk factor surveillance is important among populations undergoing rapid changes in health and can help in developing interventions. It is important for FN, Inuit and Métis governing bodies to understand and act upon issues that affect their people specifically because each of these Aboriginal groups represent distinct groups with unique relationships to the federal, provincial and local governments. Therefore, Aboriginal groups require data that are relevant to their own people, regardless of jurisdiction.

To date there has been scant research comparing chronic disease and risk and protective factor prevalence in the three Aboriginal populations in northern Canada. The purpose of our research was 1) to describe and compare the prevalence of chronic conditions and risk factors among the FN, Inuit, and Métis populations and 2) to compare these populations to northern non-Aboriginal populations.

\section{Methods}

\section{Data source}

We used data from cycles $3.1(2005 / 2006)$ and $4.1(2007 / 2008)$ of the Canadian Community Health Survey (CCHS) for this

* The proportions do not sum 100 because those who identified with more than one ethnic group have been excluded.

\section{Author references:}

Department of Community Health Sciences, Faculty of Medicine, University of Manitoba, Winnipeg, Manitoba, Canada

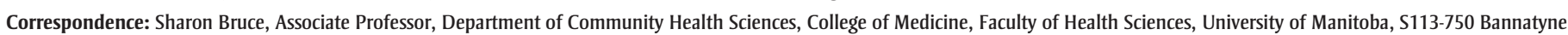
Avenue, Winnipeg, MB R3E 0W3; Tel.: 204-975-7745; Fax: 204-789-3905; Email: sharon.bruce@med.umanitoba.ca 
research. The CCHS is a national survey conducted by Statistics Canada that contains questions about health care status, determinants of health and health system use for 136 health regions in Canada. The CCHS covers approximately $98 \%$ of the entire Canadian population aged 12 years or older. People living on Indian reserves and other government-owned land and in institutions as well as full-time members of the Canadian Forces are excluded from the survey. In Yukon and Nunavut, Aboriginal people do not live on reserve, nor do over $99 \%$ of the people in NWT. ${ }^{5}$ In Nunavut, the CCHS only collects information from the 10 largest communities; therefore $71 \%$ of the population of this territory is covered by the survey. ${ }^{6}$ Data from the two CCHS cycles were combined to allow adequate sample size to investigate multiple chronic diseases and risk factors.

Sample sizes for cycles 3.1 and 4.1 of the CCHS were 132947 and 131 959, respectively. Response rates for cycle 3.1 were $78.9 \%$ for the total Canadian sample, $81.6 \%$ for Yukon, $81.7 \%$ for NWT and $87.7 \%$ for Nunavut. In cycle 4.1 , response rates were $76.4 \%$ for total Canadian sample, $83.0 \%$ for Yukon, $85.0 \%$ for NWT and $85.4 \%$ for Nunavut. Included in this study are all respondents to cycle 3.1 or cycle 4.1 aged 20 years and older who reported Yukon, NWT or Nunavut as their region of residence. Therefore, the non-Aboriginal comparison population is also northern.

Our research was approved by the University of Manitoba Health Research Ethics Board. Statistics Canada approved access to the data; analyses were conducted within the secure environment of the Statistics Canada Research Data Centre located at the University of Manitoba.

\section{Study measures}

In each cycle of the CCHS, respondents were asked if they self-identified with one of the three constitutionally recognized Aboriginal groups. Those who identified with more than one ethnic group were assigned to the FN group. Given the small sample size, we did not want to exclude any individuals. Respondents who selected an ethnic group other than the three
Aboriginal groups were defined as nonAboriginal. Therefore, the ethnic categories for this study are FN, Inuit, Métis and nonAboriginal.

In addition to age and sex, respondents were characterized by total household income and highest level of education. Education was categorized as less than secondary, secondary and post-secondary. Respondents were asked to provide an estimate of total household income from all sources, before taxes and deductions, in the past 12 months; total household income was assigned to one of four categories: $\$ 0$ to $\$ 29$ 999, \$30 000 to $\$ 59$ 999, \$60 000 to $\$ 99$ 999, and $\$ 100000$ or more.

Respondents were asked about long-term chronic health conditions that were expected to last, or had already lasted 6 months or more and been diagnosed by a health care professional. Multiple chronic conditions are included in this analysis: arthritis/rheumatism, asthma, bowel disorders, cancer, diabetes, emphysema/ chronic obstructive pulmonary disease (COPD), heart disease, high blood pressure and stroke. Dichotomous variables (i.e. presence/absence) were created for each condition. In addition, a single variable was created for an individual's overall level of morbidity. Specifically, the presence of at least one of the following chronic conditions was used to create a binary morbidity variable: arthritis/rheumatism, asthma, high blood pressure, diabetes, heart disease, cancer, stroke, chronic bronchitis, emphysema, COPD, bowel disorders, anxiety disorder, mood disorder, migraine headaches, dementia, stomach or intestinal ulcers, urinary incontinence and back problems.

We also investigated a number of risk and protective factors including alcohol consumption, cigarette smoking, body mass index (BMI) and leisure-time and regular physical activity. Risk factors included as part of the optional module in the CCHS were excluded. We categorized alcohol consumption as follows: non-drinker; occasional ( $<1 \mathrm{drink} / \mathrm{month}$ in the past 12 months); regular ( $\geq 1 \mathrm{drink} /$ month in the past 12 months); and heavy ( $\geq 5$ drinks on at least one occasion in the past 12 months). ${ }^{7}$ Possible responses on the frequency of cigarette smoking were daily, occasionally or non-smoker. Dichotomous variables (yes/no) were created for each category; for example, odds ratio for daily smoking are reported as compared to nonsmokers. Variables were dichotomized to improve interpretation and also minimize the effect of small cell sizes as we crosstabulated with the explanatory variables. We determined the chronic conditions and risk factors to select based on availability in the dataset as well as theoretical considerations; many of the chronic conditions have already been implicated in the epidemiological transition that is emerging in the north. ${ }^{4,8}$ All of the risk factors were related to multiple chronic conditions, are inter-related and/or are markers of broader community and structural factors. For example, alcohol use is associated with heart disease, blood pressure, anxiety disorders, mood disorders and bowel disorders. ${ }^{9-11}$ Smoking is associated with asthma, chronic bronchitis, diabetes, heart disease and high blood pressure. $^{12}$ Overweight and obesity are associated with arthritis, asthma, diabetes, heart disease, high blood pressure, bowel disorders, anxiety disorders and mood disorders. ${ }^{13,14}$

BMI was calculated from self-reported height and weight data. ${ }^{15}$ Overweight was defined as BMI of 25.00 to $29.99 \mathrm{~kg} / \mathrm{m}^{2}$ and obesity as BMI of $30.0 \mathrm{~kg} / \mathrm{m}^{2}$ or higher. ${ }^{16}$

Respondents were asked to report the frequency of all physical activities not related to work lasting over 15 minutes for the 3-month period before the date of the interview. Average monthly frequency was then calculated. Physical activity level was categorized as follows: regular $(\geq 12$ occasions/month); occasional (4-11 occasions/month); and infrequent ( $<4$ occasions/month). Dichotomous variables (yes/ no) were formed for each category of physical activity. Levels of leisure-time physical activity were derived based on each respondent's total daily energy expenditure during leisure-time physical activities $^{17}$ and was defined as active ( $\geq 3.0 \mathrm{kcal} /$ $\mathrm{kg} /$ day), moderate $(1.5-2.99 \mathrm{kcal} / \mathrm{kg} /$ day $)$ or inactive $(0-1.49 \mathrm{kcal} / \mathrm{kg} /$ day $)$. Leisuretime physical activities included walking, running, cycling, swimming, home exercise, exercise classes, fishing and gardening and 
also playing team sports such as ice hockey, basketball, volleyball and soccer. Each category of leisure-time physical activities was dichotomized (yes/no).

Finally, we investigated an overall measure of health. Respondents were asked to rate their own health with 5 options ranging from excellent to poor. Subsequently, we combined the 5 categories of self-rated health into 2: excellent, very good and good in one, and fair and poor in the other. (For further information on self-rated health in indigenous populations, see Bombak and Bruce SG. ${ }^{18}$ )

\section{Data analysis}

Data from the two cycles were combined using a pooled estimate method. ${ }^{19}$ Descriptive analyses of the total number of respondents and their sociodemographic characteristics were conducted in an unweighted analysis. Crude prevalence of the selected chronic diseases, risk factors and self-rated health were calculated with $95 \%$ confidence intervals (CIs) using the sampling weights, which ensures that the estimates are representative of the study population.

Weighted multiple logistic regression analyses were used to test the association between ethnicity and each of the mea- sures of chronic disease, health risk and self-rated health. In addition to ethnic group, the covariates included age group (20-34 years, 35-54 years, 55+ years), sex, territory of residence, education level and total household income. The reference categories were the 55+ years age group, male sex, non-Aboriginal ethnicity for analyses that included all ethnic groups and FN for within-Aboriginal group analyses, NWT residence, less than secondary education and lowest income category (\$0-\$29 999).

We used a bootstrap method to calculate 95\% CIs for the crude prevalence estimates and adjusted odds ratios (AORs)..$^{20,21}$ The bootstrap method randomly samples, with replacement from the original set of observations, to obtain a sampling distribution for a population parameter. We conducted all analyses with a SAS ${ }^{22}$ macro developed by methodologists at Statistics Canada; it was based on a total of 500 samples, as recommended by the software developers.

\section{Results}

Table 1 shows the sociodemographic characteristics of the study population. Missing data were minimal $(<1 \%)$. FN and Inuit populations were younger than the nonAboriginal population; $59 \%$ and $74 \%$ of FN and Inuit, respectively, were aged less than 45 years compared to $50 \%$ of the nonAboriginal population. The age structure of the Métis population is similar to the nonAboriginal population. Educational attainment is lower among Aboriginal populations compared to the non-Aboriginal population. Annual income is also lower for FN and Inuit populations compared to the Métis and non-Aboriginal populations.

Crude prevalence and AORs for the chronic conditions and risk factors are shown in Tables 2 and 3, respectively; the nonAboriginal population is the reference group for the regression models. The AOR for at least one chronic condition was significantly lower for Inuit than for nonAboriginal population, but similar among FN, Métis and non-Aboriginal populations. The most common chronic conditions for all populations were arthritis and high blood pressure. The AOR for diabetes was significantly lower among the Inuit than among the non-Aboriginal population. Other chronic diseases such as asthma, bowel disorders (e.g. Crohn's disease, ulcerative colitis or irritable bowel syndrome) and mood disorders (e.g. depression) were also significantly less likely among the Inuit than among the nonAboriginal population. Odds of reporting an anxiety disorder are significantly higher among the Métis than the non-Aboriginal

TABLE 1

Sociodemographic characteristics of northern Canadian population, $\geq 20$ years, 2005 and 2008

\begin{tabular}{|c|c|c|c|c|c|c|c|c|c|}
\hline \multicolumn{2}{|c|}{ Characteristics } & \multicolumn{2}{|c|}{ First Nations } & \multicolumn{2}{|c|}{ Métis } & \multicolumn{2}{|c|}{ Inuit } & \multicolumn{2}{|c|}{ Non-Aboriginal } \\
\hline & & n & $\%$ & n & $\%$ & n & $\%$ & $\mathbf{n}$ & $\%$ \\
\hline \multirow[t]{2}{*}{ Sex } & Male & 363 & 43.9 & 97 & 44.9 & 452 & 48.5 & 1486 & 49.6 \\
\hline & Female & 468 & 56.3 & 119 & 55.1 & 480 & 51.5 & 1511 & 50.4 \\
\hline \multirow[t]{4}{*}{ Age group, years } & $20-34$ & 282 & 33.9 & 67 & 31.0 & 444 & 47.6 & 851 & 28.4 \\
\hline & $35-44$ & 204 & 24.6 & 58 & 26.9 & 245 & 26.3 & 649 & 21.7 \\
\hline & $45-54$ & 147 & 17.7 & 55 & 25.5 & 113 & 12.1 & 727 & 24.3 \\
\hline & $\geq 55$ & 198 & 23.8 & 36 & 16.7 & 130 & 14.0 & 770 & 25.7 \\
\hline \multirow[t]{3}{*}{ Education } & $<$ Secondary & 374 & 45.0 & 49 & 22.7 & 428 & 45.9 & 281 & 9.4 \\
\hline & Secondary school graduation & 74 & 8.9 & 26 & 12.0 & 68 & 7.3 & 325 & 10.8 \\
\hline & Post-secondary education & 377 & 45.4 & 141 & 65.3 & 429 & 46.0 & 2379 & 79.4 \\
\hline \multirow[t]{4}{*}{ Total household income, \$ } & 0-29999 & 277 & 33.3 & 32 & 14.8 & 304 & 32.6 & 345 & 11.5 \\
\hline & $30000-59999$ & 166 & 20.0 & 40 & 18.5 & 193 & 20.7 & 520 & 17.4 \\
\hline & $60000-99999$ & 127 & 15.3 & 46 & 21.3 & 147 & 15.8 & 801 & 26.7 \\
\hline & $>100000$ & 107 & 12.9 & 74 & 34.3 & 122 & 13.1 & 1095 & 36.5 \\
\hline Total sample (N) & & 831 & 16.6 & 216 & 4.3 & 932 & 18.6 & 2997 & 59.8 \\
\hline
\end{tabular}


TABLE 2

Crude prevalence (\%) of chronic diseases and risk/protective factors by ethnic group, 2005 and 2008

\begin{tabular}{|c|c|c|c|c|}
\hline & \multicolumn{4}{|c|}{ Prevalence, \% (95\% CI) } \\
\hline & First Nations & Métis & Inuit & Non-Aboriginal \\
\hline \multicolumn{5}{|l|}{ Chronic disease } \\
\hline Arthritis & $12.43(9.46-15.39)$ & $14.03(8.92-19.14)$ & $11.02(8.11-13.92)$ & 13.98 (12.44-15.52) \\
\hline Asthma & $6.43(3.86-8.99)$ & $7.90(4.09-11.71)$ & $3.51(1.78-5.23)$ & 8.38 (7.09-9.67) \\
\hline Heart disease & $3.31(1.69-4.92)$ & $3.94(0.75-7.14)$ & $2.14(0.85-3.42)$ & $2.73(1.97-3.50)$ \\
\hline High blood pressure & $13.45(10.32-16.58)$ & $12.88(7.16-18.61)$ & 7.76 (5.97-9.56) & $12.82(11.26-14.39)$ \\
\hline Anxiety disorder & $3.66(2.26-5.06)$ & 6.58 (3.43-9.74) & $2.63(0.69-4.57)$ & $3.65(2.68-4.62)$ \\
\hline Bowel disorder & $3.43(1.47-5.39)$ & $4.55(0.81-8.28)$ & $0.80(0.00-1.70)$ & $4.18(3.13-5.23)$ \\
\hline Regular drinking $^{b}$ & $54.84(49.14-60.53)$ & $67.95(60.54-75.36)$ & 45.15 (37.47-52.84) & $67.48(64.42-70.55)$ \\
\hline Daily smoker & 45.13 (40.97-49.28) & 33.07 (24.77-41.37) & 63.62 (59.21-68.03) & $22.84(20.33-25.35)$ \\
\hline Overweight $^{c}$ & $29.04(25.58-32.51)$ & 31.52 (22.19-40.85) & $26.75(23.48-30.01)$ & 33.52 (31.25-35.79) \\
\hline Obesity $^{d}$ & $23.55(18.54-28.56)$ & $28.28(20.43-36.12)$ & $24.27(20.48-28.06)$ & $21.05(19.06-23.03)$ \\
\hline Active during leisure time $\mathrm{e}^{\mathrm{e}}$ & $19.37(14.54-24.21)$ & 18.83 (12.94-24.73) & $18.48(14.73-22.24)$ & $23.34(20.77-25.90)$ \\
\hline Regular physical activity ${ }^{f}$ & 55.38 (49.30-61.47) & $57.08(49.15-65.00)$ & $47.52(42.57-52.47)$ & $65.35(62.72-67.98)$ \\
\hline Self-perceived health ${ }^{g}$ & 82.64 (79.49-85.79) & 88.51 (82.20-94.82) & 82.98 (79.83-86.13) & 91.05 (89.42-92.68) \\
\hline
\end{tabular}

Abbreviations: BMI, body mass index; $\mathrm{Cl}$, confidence interval.

a $\geq 5$ drinks on at least one occasion in the past 12 months.

b $\geq 1 \mathrm{drink} /$ month in the past 12 months.

c BMI 25.00-29.99 kg/m².

${ }^{\mathrm{d}} \mathrm{BMI} \geq 30.0 \mathrm{~kg} / \mathrm{m}^{2}$.

e $\geq 3.0 \mathrm{kcal} / \mathrm{kg} /$ day.

f $\geq 12$ occasions/month.

83 categories of self-rated health in one category: excellent, very good and good.

population. The odds of reporting a chronic illness were not significantly different between northern FN and non-Aboriginal respondents.

The prevalence of many chronic disease risk factors, however, was significantly higher among Aboriginal than non-Aboriginal population. Some of these results are highlighted in Figure 1. Compared to nonAboriginal respondents, larger proportions of FN, Inuit and Métis respondents reported binge drinking. Odds of binge drinking among $\mathrm{FN}$ and Inuit respondents were about twice that of non-Aboriginal respondents. The prevalence of daily smoking was also higher among all Aboriginal populations than the non-Aboriginal population, and ranged from $64 \%$ for the Inuit to $23 \%$ for the non-Aboriginal population. The AOR of daily smoking was 3.5 times higher for the Inuit, twice as high for FN and 1.5 times higher for the Métis.

About $30 \%$ of all respondents were overweight, and prevalence of obesity ranged from $24 \%$ to $28 \%$ for FN, Inuit and Métis respondents to $21 \%$ for non-Aboriginal respondents. The AOR of obesity for the Métis is 1.51 times that of the nonAboriginal population. The percentage of FN, Inuit and Métis respondents reporting regular physical activity and leisure-time physical activity is lower than for nonAboriginal respondents. A high proportion of all respondents reported their health as either excellent, very good or good, from $83 \%$ for FN and Inuit respondents, to $91 \%$ for non-Aboriginal respondents. However, the AOR of reporting excellent, very good and good health was significantly lower for Inuit than for non-Aboriginal populations.

AORs for the chronic conditions and risk factors in the three Aboriginal groups are shown in Table 4; the FN population is the reference group. Odds of diabetes and bowel disorders were significantly lower among the Inuit than among the FN population. In terms of risk factors, the AORs of being a regular drinker or of being overweight were significantly lower for Inuit than for FN populations. The odds of being a regular drinker are significantly higher for the Métis than the FN population. No other differences in odds of 
TABLE 3

Adjusted odds ratios for major chronic disease and risk/protective factors by ethnic group, 2005 and 2008

\begin{tabular}{|c|c|c|c|}
\hline & \multicolumn{3}{|c|}{ AOR $(95 \% \mathrm{CI})$} \\
\hline & First Nations & Métis & Inuit \\
\hline \multicolumn{4}{|l|}{ Chronic disease } \\
\hline At least 1 chronic condition & $0.95(0.72-1.27)$ & $1.09(0.72-1.66)$ & $0.59(0.43-0.81)^{\mathrm{a}}$ \\
\hline Arthritis & $0.70(0.48-1.03)$ & $1.06(0.67-1.68)$ & $0.90(0.56-1.46)$ \\
\hline Asthma & $0.69(0.42-1.13)$ & $0.92(0.50-1.68)$ & $0.48(0.24-0.96)^{\mathrm{a}}$ \\
\hline Chronic bronchitis & $1.00(0.41-2.49)$ & $2.24(0.20-24.74)$ & $0.68(0.11-4.40)$ \\
\hline Diabetes & $1.26(0.75-2.13)$ & $1.58(0.64-3.90)$ & $0.36(0.14-0.88)^{\mathrm{a}}$ \\
\hline Heart disease & $0.91(0.48-1.72)$ & $1.81(0.55-5.92)$ & $1.06(0.45-2.49)$ \\
\hline High blood pressure & $1.12(0.74-1.69)$ & $1.22(0.68-2.21)$ & $0.77(0.51-1.17)$ \\
\hline Anxiety disorder & $1.02(0.61-1.68)$ & $2.07(1.07-4.03)^{\mathrm{a}}$ & $0.75(0.32-1.79)$ \\
\hline Bowel disorder & $0.63(0.33-1.22)$ & $1.03(0.41-2.56)$ & $0.15(0.05-0.41)^{\mathrm{a}}$ \\
\hline Mood disorder & $0.66(0.42-1.03)$ & $0.76(0.32-1.78)$ & $0.37(0.19-0.72)^{\mathrm{a}}$ \\
\hline \multicolumn{4}{|l|}{ Risk factor } \\
\hline Binge drinking ${ }^{b}$ & $2.19(1.58-3.04)^{\mathrm{a}}$ & $1.46(0.91-2.34)$ & $1.85(1.23-2.78)^{\mathrm{a}}$ \\
\hline Regular drinking ${ }^{c}$ & $0.77(0.57-1.03)$ & $1.12(0.74-1.68)$ & $0.46(0.31-0.67)^{\mathrm{a}}$ \\
\hline Daily smoker & $2.09(1.60-2.74)^{\mathrm{a}}$ & $1.54(1.07-2.21)^{\mathrm{a}}$ & $3.48(2.43-4.98)^{\mathrm{a}}$ \\
\hline Overweight $^{d}$ & $0.94(0.73-1.21)$ & $0.89(0.55-1.44)$ & $0.79(0.58-1.07)$ \\
\hline Obese $^{\mathrm{e}}$ & $1.36(0.98-1.89)$ & $1.51(1.03-2.19)^{\mathrm{a}}$ & $1.37(0.93-2.03)$ \\
\hline Leisure physical activity: active ${ }^{f}$ & $0.96(0.68-1.37)$ & $0.88(0.56-1.39)$ & $0.82(0.59-1.12)$ \\
\hline Regular physical activity ${ }^{g}$ & $0.93(0.69-1.25)$ & $0.84(0.59-1.18)$ & $0.76(0.55-1.05)$ \\
\hline Self-perceived health ${ }^{\mathrm{h}}$ & $0.72(0.52-0.99)$ & $0.84(0.41-1.71)$ & $0.55(0.34-0.88)^{\mathrm{a}}$ \\
\hline
\end{tabular}

Abbreviations: AOR, adjusted odds ratio; BMI, body mass index; $\mathrm{Cl}$, confidence interval.

Notes: AORs are adjusted for age, sex, region, income and education.

The reference group is the non-Aboriginal population.

a Denotes an estimate that is statistically significant at the $5 \%$ level of significance.

b $\geq 5$ drinks on at least one occasion in the past 12 months.

c $\geq 1 \mathrm{drink} /$ month in the past 12 months.

${ }^{\mathrm{d}} \mathrm{BMI}=25.00-29.99 \mathrm{~kg} / \mathrm{m}^{2}$.

e $B M I \geq 30.0 \mathrm{~kg} / \mathrm{m}^{2}$.

$\mathrm{f} \geq 3.0 \mathrm{kcal} / \mathrm{kg} /$ day.

$8 \geq 12$ occasions/month.

h 3 categories of self-rated health in 1 category: excellent, very good and good.

chronic conditions, risk factors or self-rated health were found among the Aboriginal groups.

\section{Discussion}

Variability in chronic disease and risk factor prevalence was found among $\mathrm{FN}$, Inuit and Métis residents of northern Canada. Most research and chronic disease surveillance reports for northern Canada have, to date, combined the three ethnic groups into one-Aboriginalgroup. However, the three groups have different histories, cultural backgrounds and lifeways, all of which may have influenced the differences in outcomes and will affect interventions to address them.

Among the Inuit, prevalence of chronic disease was lower than among the northern FN and Métis populations. This is consistent with previous findings related to diabetes, ${ }^{23,24}$ although inter-ethnic differences regarding other chronic diseases have not been investigated. Lix et al. previously reported on the prevalence of chronic disease and risk factors for southern Aboriginal people (i.e. residents of the
10 Canadian provinces) using 2005/2006 CCHS data. ${ }^{4}$ Compared to Aboriginal populations in southern Canada, the prevalence of arthritis, asthma, heart disease, diabetes and high blood pressure is lower among the Inuit. Prevalence of chronic disease risk factors is more variable. The Inuit were similar to northern $\mathrm{FN}$ and Métis on most of the risk factors investigated in this research. However, compared to southern Aboriginal populations, the Inuit have lower prevalence of overweight and regular drinking but similar levels of obesity and higher prevalence of binge drinking and daily smoking. ${ }^{4}$

We previously also reported on chronic disease and risk factor prevalence among northern Aboriginal and non-Aboriginal populations by territory of residence (i.e. NWT, Yukon and Nunavut). ${ }^{8}$ The prevalence of most chronic disorders among the Inuit has not increased and risk factor prevalence has stayed the same or increased, compared to Aboriginal data for Nunavut. Specifically, prevalence of overweight and obesity has not changed, but daily smoking, regular drinking and binge drinking have increased. ${ }^{8}$

That the prevalence of chronic disease among the Inuit remains the lowest for all Aboriginal people in Canada and has generally not increased since 2000 is positive. This may be attributable to greater adherence to traditional lifestyles including dietary patterns among this group. However, the literature also suggests the beginning of a shift to western diets. ${ }^{25}$ On the other hand, the increasing prevalence of risk factors among the Inuit is worrying. The risk factors that are increasing are linked to major chronic diseases such as cancer ${ }^{26}$ and heart disease $^{27}$ and social problems like violence, accidents, injuries, addictions, and family and community dysfunction. ${ }^{28}$ This finding, together with other reported adverse changes in the health transition, ${ }^{29,30}$ suggests that some chronic conditions could be on the rise. Communities, clinicians and policy makers must work together to address the increasing risk factors and develop interventions aimed at risk factor reduction. 
FIGURE 1

Odds of selected risk factors and self-perceived health among northern Aboriginal groups compared to the northern non-Aboriginal population

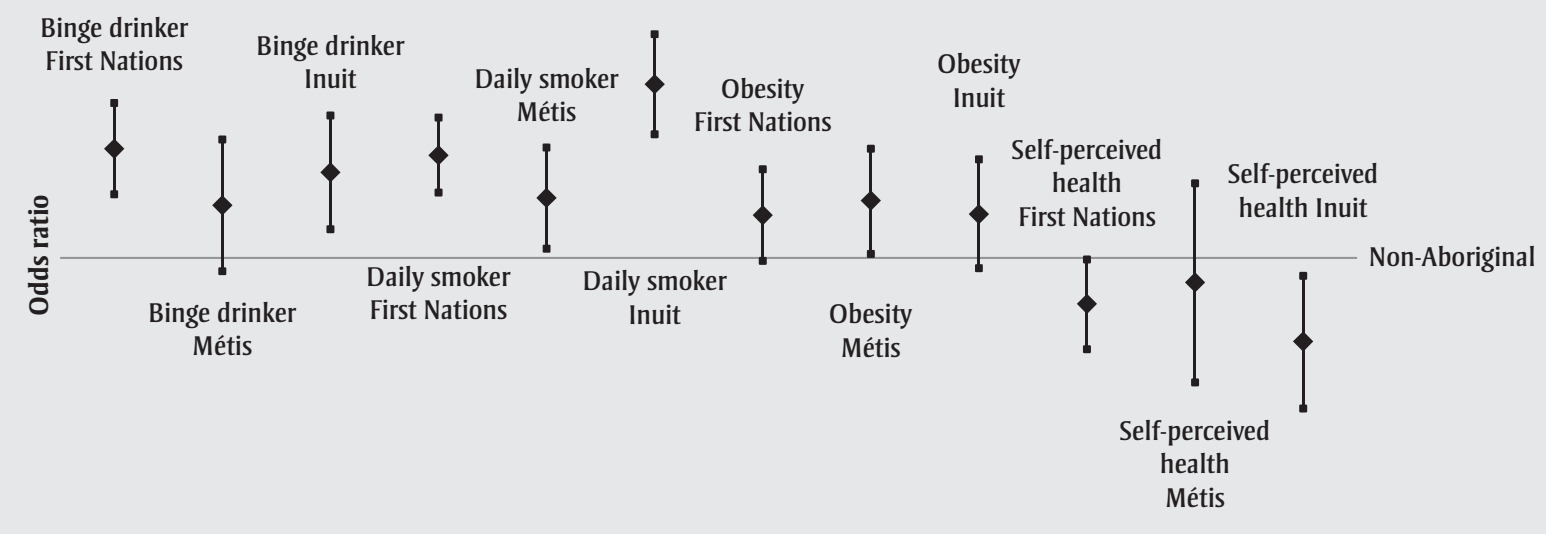

Odds of binge drinking, daily smoking, obesity and self-perceived health by ethnic group

$\bullet$ Odds ratio $\quad$ - Cl lower $\quad$ - $\mathrm{Cl}$ upper

Abbreviation: $\mathrm{Cl}$, confidence interval.

Among northern FN residents, prevalence of arthritis, asthma and heart disease is lower than among southern Aboriginal people, of diabetes is about the same, and of high blood pressure is greater. ${ }^{4}$ The picture for chronic disease risk factors is also variable. Compared to southern Aboriginal residents, $\mathrm{FN}$ residents in northern Canada have similar prevalence of overweight, obesity and regular drinking but higher prevalence of binge drinking and daily smoking. ${ }^{4}$ The chronic disease and risk factor picture for northern FN people is of concern because it has been seen before among FN people in southern Canada; chronic diseases and risk factors among Aboriginal people of southern Canada are sources of excess morbidity, decreased quality of life and premature mortality.

Finally, prevalence of arthritis, asthma and heart disease among the Métis of northern Canada is lower than among Métis of southern Canada. ${ }^{31-33}$ Compared to southern Aboriginal Canadians, the prevalence of overweight is similar, daily smoking is lower, but obesity, regular drinking and binge drinking are higher. Similar to the Inuit and northern FN, the risk factor profile of the Métis is of concern because of cardiometabolic morbidity, social consequences and premature mortality.

It will be important for northern Aboriginal communities and organizations to work with government agencies and health care professionals to decrease the risk profile if they hope to avert the epidemic of cardiometabolic conditions witnessed among Aboriginal people in southern Canada. However, the environment in the north may be more challenging because community resources are fewer, food more expensive and the effects of climate change greater. ${ }^{34,35}$

\section{Strengths and limitations}

This study is subject to limitations. CCHS data are based on self-report; this may result in underestimates of chronic disease and risk factors such as BMI, smoking and drinking. Further, commonly used cutpoints of BMI for obesity and overweight may not be appropriate for all Aboriginal populations. ${ }^{36}$ Respondents may also overestimate their overall levels of physical activity. Dietary data, although relevant to chronic disease, could not be included because these data were collected as part of an optional module of the CCHS. CCHS data apply only to
Aboriginal people living off-reserve and therefore miss the entire segment of those living on-reserve. However, FN, Inuit and Métis populations in the Yukon and Nunavut do not live on reserve; nor do over $99 \%$ of the FN people in NWT. ${ }^{5}$ As such, our sample is a good representation of Aboriginal people in northern Canada. There are, however, limitations of the identification of Aboriginal people in the CCHS. ${ }^{37}$ Pooling cycles of the CCHS, specifically the issue of re-sampling the same individuals and sample dependence is also a limitation. Lastly, the large number of comparisons may contribute to a greater likelihood of significant chance findings.

Notwithstanding these limitations, this research represents an important contribution on the health of Aboriginal peoples in Canada's north. This research is the first to compare northern FN, Inuit and Métis on chronic disease and risk factor prevalence. We found significant differences in disease and risk factors among these three Aboriginal groups. Ethnicspecific data are important to Aboriginal political organizations, government policy makers, clinicians and communities because they offer the chance to set priorities for interventions. While some 
TABLE 4

Adjusted odds ratios for major chronic disease and risk/protective factors by ethnic group, 2005 and 2008

\begin{tabular}{|c|c|c|}
\hline & \multicolumn{2}{|c|}{ AOR $(95 \% \mathrm{CI})$} \\
\hline & Métis & Inuit \\
\hline \multicolumn{3}{|l|}{ Chronic disease } \\
\hline At least 1 chronic condition & $1.19(0.74-1.91)$ & $0.64(0.39-1.06)$ \\
\hline Arthritis & $1.58(0.87-2.88)$ & $1.54(0.73-3.28)$ \\
\hline Asthma & $1.34(0.66-2.70)$ & $1.19(0.44-3.18)$ \\
\hline Chronic bronchitis & $2.04(0.18-23.01)$ & $0.67(0.06-7.58)$ \\
\hline Diabetes & $1.22(0.53-2.80)$ & $0.33(0.13-0.82)^{\mathrm{a}}$ \\
\hline Heart disease & $2.22(0.69-7.08)$ & $1.07(0.37-3.10)$ \\
\hline High blood pressure & $1.16(0.59-2.26)$ & $0.95(0.51-1.78)$ \\
\hline Anxiety disorder & $2.07(0.98-4.37)$ & $0.60(0.26-1.41)$ \\
\hline Bowel disorder & $1.91(0.64-5.68)$ & $0.27(0.07-0.97)^{\mathrm{a}}$ \\
\hline Mood disorder & $1.06(0.43-2.60)$ & $0.94(0.30-3.02)$ \\
\hline \multicolumn{3}{|l|}{ Risk/protective factor } \\
\hline Binge drinking ${ }^{b}$ & $0.78(0.47-1.30)$ & $1.73(0.91-3.31)$ \\
\hline Regular drinking $^{c}$ & $1.58(1.09-2.31)^{\mathrm{a}}$ & $0.56(0.32-0.97)^{\mathrm{a}}$ \\
\hline Daily smoker & $0.69(0.45-1.04)$ & $1.49(0.91-2.45)$ \\
\hline Overweight $^{d}$ & $0.94(0.57-1.54)$ & $0.57(0.36-0.92)^{\mathrm{a}}$ \\
\hline Obesity $^{\mathrm{e}}$ & $1.03(0.61-1.75)$ & $1.79(0.98-3.27)$ \\
\hline Active during leisure time ${ }^{f}$ & $0.88(0.50-1.56)$ & $0.56(0.29-1.09)$ \\
\hline Regular physical activity & $0.96(0.63-1.45)$ & $0.68(0.41-1.13)$ \\
\hline Self-perceived health ${ }^{h}$ & $1.18(0.60-2.33)$ & $0.64(0.36-1.13)$ \\
\hline
\end{tabular}

Abbreviations: AOR, adjusted odds ratio; BMI, body mass index; $\mathrm{Cl}$, confidence interval.

Notes: AORs are adjusted for age, sex, region, income and education.

The reference group is the First Nations population.

${ }^{a}$ Denotes an estimate that is statistically significant at the $5 \%$ level of significance.

b $\geq 5$ drinks on at least one occasion in the past 12 months.

c $\geq 1 \mathrm{drink} / \mathrm{month}$ in the past 12 months.

${ }^{\mathrm{d}} \mathrm{BMI}=25.00-29.99 \mathrm{~kg} / \mathrm{m}^{2}$.

e $\mathrm{BMI} \geq 30.0 \mathrm{~kg} / \mathrm{m}^{2}$.

f $\geq 3.0 \mathrm{kcal} / \mathrm{kg} /$ day.

$8 \geq 12$ occasions/month.

${ }^{\mathrm{h}} 3$ categories of self-rated health in 1 category: excellent, very good and good.

results are heartening, the risk factor profile among all three northern Aboriginal populations is of concern. Continued chronic disease and risk factor surveillance will be important to monitor continued changes over time and to evaluate the impact of public health interventions.

\section{Acknowledgements}

This study was supported by the Canadian Institutes of Health Research. None of the authors have a conflict of interest.
3. Waldram JB, Herring A, Young TK. Aboriginal Health in Canada: Historical, Cultural and Epidemiological Perspectives. Toronto (ON): University of Toronto Press; 2006.

4. Lix LM, Bruce S, Sarkar J, Young TK. Risk factors and chronic conditions among Aboriginal and non-Aboriginal populations. Health Rep. 2009;20(4):21-9.

5. Northwest Territories Bureau of Statistics. Hay River Reserve- Statistical Profile [Internet]. Yellowknife (NWT): Northwest Territories Bureau of Statistics; [updated 2010; accessed $2011 \mathrm{Feb} 17]$. Available from: http://www.statsnwt.ca/community-data /infrastructure/Hay_River_Reserve.html

6. Statistics Canada. Canadian Community Health Survey - Annual Component (CCHS): detailed information for 2008 [Internet]. Ottawa (ON): Statistics Canada; [modified: 2009 Jun 24; cited 2011 Feb 26]. Available from: http://www.statcan.gc.ca /cgi-bin/imdb/p2SV.pl?Function = getSurvey \&SurvId $=3226 \&$ SurvVer $=1$ \&InstaId $=15282$ \&InstaVer $=5 \&$ SDDS $=3226 \&$ lang $=$ en $\& d b=$ imdb\&adm $=8 \&$ dis $=2$

7. Reynolds DL, Chambers LW, DeVillaer MR. Measuring alcohol abuse in the community: consumption, binge-drinking, and alcoholrelated consequences ("alcoholism"). Can J Public Health. 1992;83:441-7.

8. Sarkar J, Lix LM, Bruce S, Young TK. Ethnic and regional differences in prevalence and correlates of chronic diseases and risk factors in northern Canada. Prev Chronic Dis. 2010;7(1):A13.

9. Marmot M, Brunner E. Alcohol and cardiovascular disease: the status of the $\mathrm{U}$ shaped curve. BMJ. 1991;303:565-8.

10. Milani RM, Parrott AC, Turner JJ, Fox HC. Gender differences in self-reported anxiety, depression, and somatization among ecstasy/MDMA polydrug users, alcohol/ tobacco users, and nondrug users. Addict Behav. 2004;29:965-71.

2. Bjerregaard P, Young TK, Dewailly E, Ebbesson SOE. Indigenous health in the Arctic: an overview of the circumpolar Inuit population. Scand J Public Health. 2004;32: 390-5.
11. Longstreth GF, Wolde-Tsadik G. Irritable bowel-type symptoms in HMO examinees. Digest Dis Sci. 1993;38(9):1581-9. 
12. Tverdal A, Thelle D, Stensvold I, Leren P, Bjartveit K. Mortality in relation to smoking history: 13 years' follow-up of 68,000 Norwegian men and women 35-49 years. J Clin Epidemiol. 1993;46(5):475-87.

13. Scott KM, Bruffaerts R, Tsang A, et al. Depression-anxiety relationships with chronic physical conditions: results from the World Mental Health surveys. J Affect Disorders. 2007;103:113-20.

14. Wyatt SB, Winters KP, Dubbert PM. Overweight and obesity: prevalence, consequences, and causes of a growing public health problem. Am J Med Sci. 2006;331(4): 166-74.

15. Statistics Canada. Canadian Community Health Survey cycle 4.1: user guide 20072008 microdata files. Ottawa (ON): Statistics Canada; 2009.

16. Health CanadaCanadian guidelines for body weight classification in adults. Ottawa $(\mathrm{ON})$ : Health Canada, Office of Nutrition Policy and Promotion; 2003.

17. Rao JN, Wu CF, Yue K. Some recent work on resampling methods for complex surveys. Survey Methodol. 1996;18:209-17.

18. Bombak AE, Bruce SG. Self-rated health and ethnicity: focus on indigenous populations. Int J Circumpolar Health. 2012;71:18538.

19. Thomas S, Wannell B. Combining cycles of the Canadian community health survey. Health Rep. 2009;20(1):53-8.

20. Rust KF, Rao J. Variance estimation for complex surveys using replication techniques. Stat Methods Med Res. 1996;5:283310.

21. Yeo D, Mantel H, Liu TP. Bootstrap variance estimation for the national population health survey. Proceedings of the Annual Meeting of the American Statistical Association, Survey Research Methods Section. Baltimore (MD): American Statistical Association; 1999.

22. SAS Institute I. SAS/STAT user's guide. Version 9.2. Cary (NC): SAS Institute; 2009.

23. Young TK, Szathmary EJ, Evers S, Wheatley B. Geographical distribution of diabetes among the native population of Canada: a national survey. Soc Sci Med. 1990;31:129-39.
24. Young TK, Schraer CD, Shubnikoff EV, Szathmary EJ, Nikitin YP. Prevalence of diagnosed diabetes in circumpolar indigenous populations. Int J Epidemiol. 1992;21: 730-6.

25. Sharma S, Hopping BN, Roache C, Sheehy T. Nutrient intakes, major food sources and dietary inadequacies of Inuit adults living in three remote communities in Nunavut, Canada. J Hum Nutr Diet. 2013;26:578-86.

26. Roberts DL, Dive C, Renehan AG. Biological mechanisms linking obesity and cancer risk: new perspectives. Ann Rev Med. 2010; 61:301-16.

27. Hubert HB, Feinleib M, McNamara PM, Castelli WP. Obesity as an independent risk factor for cardiovascular disease: A 26-year follow-up of participants in the Framingham Heart Study. Circulation. 1983;67(5):968-77.

28. Rehm J, Mathers C, Popova S, Thavorncharoensap M, Teerawattananon Y, Patra J. Global burden of disease and injury and economic cost attributable to alcohol use and alcohol-use disorders. Lancet. 2009;373: 2223-33.

29. Riva M, Plusquellec P, Juster RP, et al. Household crowding is associated with higher allostatic load among the Inuit. J Epidemiol Commun Health. 2014;68(4):3639. DOI:10.1136/jech-2013-203270.

30. Kral M. "The weight on our shoulders is too much, and we are falling": suicide among Inuit male youth in Nunavut, Canada. Med Anthropol Q. 2013;27(1):6383.

31. Martens P, Bartlett J, Burland E, et al. Profile of Metis health status and healthcare utilization in Manitoba: a population-based study. Winnipeg (MB): Manitoba Centre for Health Policy; 2010.

32. Janz T, Seto T, Turner A. Aboriginal peoples survey, 2006: an overview of the health of the Métis population [Internet]. Ottawa (ON): Statistics Canada; 2009 [cited: 2013 Dec 9]. Available from: http://www.statcan.gc.ca/pub/89-637-x/89 -637-x2009004-eng.htm

33. Bruce S. Prevalence and determinants of diabetes mellitus among the Metis of western Canada. Am J Hum Biol. 2000;12(4): $542-51$.
34. Wakegijig J, Osborne G, Statham S, Issaluk MD. Collaborating toward improving food security in Nunavut. Int $\mathrm{J}$ Circumpolar Health. 2013;72:21201.

35. Willox AC, Harper SL, Ford JD, et al. Climate change and mental health: an exploratory case study from Rigolet, Nunatsiavut, Canada. Clim Change. 2013;121:255-70.

36. Lear SA, Humphries KH, Kohli S, Birmingham CL. The use of BMI and waist circumference as surrogates of body fat differs by ethnicity. Obesity. 2007;15(11): 2817-24

37. Chan WW, Ng C, Young TK. How we identify and count Aboriginal people - does it make a difference in estimating their disease burden? Chronic Dis Inj Can. 2013;33(4):277-80. 